\title{
Quality of recovery from anesthesia of patients undergoing balanced or total intravenous general anesthesia. Prospective randomized clinical trial ${ }^{2}$, 弥弥,
}

\author{
Eduardo Toshiyuki Moro MD, PhD (Assistant Professor) ${ }^{a, *}$, \\ Fábio Caetano Oliveira Leme MD (Resident of Anesthesiology) ${ }^{a}$, \\ Bernardo Roveda Noronha MD (Resident of Anesthesiology) ${ }^{a}$, \\ Gustavo Farinha Pinto Saraiva (Graduate Medical Student) ${ }^{\text {b }}$, \\ Nathália Vianna de Matos Leite (Graduate Medical Student) ${ }^{\mathbf{b}}$, \\ Laís Helena Camacho Navarro MD, PhD (Assistant Professor) ${ }^{c}$
}

${ }^{a}$ Department of Surgery, School of Medical and Health Sciences, Pontifical Catholic University of São Paulo, PUC-SP, São Paulo, SP, Brazil

${ }^{\mathrm{b}}$ School of Medical and Health Sciences, Pontifical Catholic University of São Paulo, PUC-SP, São Paulo, SP, Brazil

${ }^{\mathrm{c}}$ Department of Anesthesiology, Botucatu Medical School, São Paulo State University—UNESP, Botucatu, SP, Brazil

Received 23 September 2015; accepted 9 August 2016

\section{Keywords:}

Intravenous anesthesia; Inhalation anesthesia;

Recovery from anesthesia;

Quality measures;

Patient satisfaction;

Questionnaire

\begin{abstract}
Study objectives: The aim of the present study was to assess the quality of recovery from anesthesia of patients subjected to otorhinolaryngological (ORL) surgery under balanced or total intravenous general anesthesia by means of Quality of Recovery-40 (QoR-40) questionnaire.

Design: Prospective randomized clinical trial.

Setting: The setting is at an operating room, a postoperative recovery area, and a hospital ward.

Patients: One-hundred thirty American Society of Anesthesiologists physical status I or II patients scheduled to undergo general anesthesia for ORL interventions under remifentanil, in combination with sevoflurane (balanced technique) or propofol (total intravenous anesthesia).

Measurements: Occurrence of nausea, vomiting, body temperature less than $36^{\circ} \mathrm{C}$, and length of stay in the postanesthesia care unit were recorded. The QoR-40 was administered by an investigator blind to group allocation 24 hours after surgery. The quality of recovery, as assessed by the score on the QoR-40, was compared between the groups.
\end{abstract}

\footnotetext{
Funding: None

岤 Attestation: ETM and LHCN attest to the integrity of the original data and the analysis reported in this manuscript. FCOL, BRN, FPS, and NVdML approved the final manuscript.

^ Conflicts of interest: All authors have no conflicts of interest to report.

* Corresponding author at: Avenida Araçoiaba, 85, Condomínio Lago Azul, Araçoiaba da Serra, SP 18190-000, Brazil. Tel.: +55 15 3281 3146 ; fax: +55 15 3212 9900 .

E-mail addresses: eduardo_moro@terra.com.br, edumoro85@gmail.com (E.T. Moro), fabio.leme@hotmail.com (F.C.O. Leme), bernardorn@gmail.com (B.R. Noronha), gustavofps@gmail.com (G.F.P. Saraiva), nathalia_vianna@hotmail.com (N.V. de Matos Leite), laishnavarro@fmb.unesp.br (L.H.C. Navarro).
} 
Main results: There is no difference regarding the QoR-40 score among intravenous and inhalation anesthesia groups (190.5 vs 189.5 , respectively; $P=.33$ ). Similarly, among the 5 dimensions of the QoR40 , the scores were comparable between the groups. Incidence of hypothermia $(P=.58)$, nauseas or vomits $(P=.39)$, and length of surgery $(P=.16)$ were similar among groups. The evaluation of pain intensity $(P=.80)$ and dose of morphine use in the postanesthesia care unit $(P=.4)$ was also comparable between groups.

Conclusions: The quality of recovery from anesthesia assessed based on the patients' perception did not differ between the ones subjected to either inhalation or intravenous general anesthesia for ORL surgery based on QoR-40 questionnaire assessment.

(C) 2016 Elsevier Inc. All rights reserved.

\section{Introduction}

General anesthesia can be performed with intravenous and/ or inhalation anesthetics. The most common agents used in everyday practice for such purposes are sevoflurane (inhalation anesthesia) and propofol (intravenous anesthesia). Although a large number of studies have been conducted to establish which technique is best, both exhibit specific advantages as a function of the assessed outcomes: nausea, vomiting, pain, cost, speed of recovery of cognitive functions, cardioprotection, and patient satisfaction [1]. Concerning patient satisfaction, an increasing number of authors have been assessing the quality of recovery from anesthesia by measures that probes quality of life from the perspective of the patient [1-3]. Quality of Recovery-40 (QoR-40) questionnaire, a validated instrument to assess the quality of recovery from anesthesia, allows for an objective evaluation of the factors that might influence the patients' perception upon comparing different therapeutic approaches [2]. A recent study using the QoR-40 questionnaire showed that the quality of recovery for female patients who underwent thyroid surgery was significantly better when intravenous anesthesia was used when compared with inhalation anesthesia with desflurane [4]. However, no study has yet used the QoR-40 to assess the quality of recovery of patients from both sexes undergoing intravenous anesthesia with propofol and remifentanil vs balanced anesthesia with sevoflurane and remifentanil.

Accordingly, the primary objective of the study was to assess the quality of recovery from anesthesia of patients undergoing otorhinolaryngological (ORL) surgical procedures under balanced or total intravenous general anesthesia through the application of the QoR-40 questionnaire. As secondary outcomes, we also assessed the rates of postoperative nausea, vomiting, and pain for each anesthetic technique.

\section{Materials and methods}

This double-blind, randomized trial was approved by the Research Ethics Committee of the School of Medical and Health Sciences, Pontifical Catholic University of São Paulo (Pontifícia Universidade Católica de São Paulo),
CAAE 17618013.3.0000.5373 (http://aplicacao.saude.gov. $\mathrm{br} /$ plataformabrasil). Written consent form was obtained from all participants. One-hundred thirty patients aged 18 to 65 years, with an American Society of Anesthesiologists physical status I or II [5], who were scheduled to undergo general anesthesia for ORL surgery at Santa Lucinda Hospital were enrolled in the study. Patients who (i) refused to participate in the study; (ii) were not able to communicate due to alterations in the level of consciousness, or neurologic, or psychiatric disease; (iii) presented with contraindication to any of the drugs used in the present study; (iv) had history of alcohol or drug dependence; (v) were super obese as defined by a body mass index $\geq 40 \mathrm{~kg} / \mathrm{m}^{2}$; and (vi) underwent uvulopalatopharyngoplasty (because he/she exhibits higher potential for postoperative pain compared with the other procedures) were excluded from the study. Importantly, items (iv) and (v) represent conditions liable to alter the pharmacokinetic and pharmacodynamic behaviors of the intravenous and inhalation anesthetics and, therefore, were exclusion criteria in the present study [6-8].

The internal consistency and Cronbach $\alpha$ and split-half correlations of the QoR-40 questionnaire were assessed in a pilot study conducted with 30 patients. The sample size for the following step was calculated considering $80 \%$ power to detect a 10-point difference in QoR-40 [9], which indicated the need to include 50 participants in each group. Taking possible losses into consideration, the final sample included 130 participants, which were allocated to 2 groups according to a random number sequence from a Web-based random-number generator (available at www.random.com). Because of significant difference between the anesthetic techniques, the anesthesia provider could not be blinded to group identity. However, both the patient and the investigators were blinded to group allocation. The anesthetic technique to be used for each individual participant was kept in an opaque and sealed envelope, which was opened at the time of surgery.

No participant took any preanesthetic medication before surgery. After arrival in the operating room, standard American Society of Anesthesiologists monitors were applied. Midazolam $0.06 \mathrm{mg} \mathrm{kg}^{-1}$ and $1 \%$ lidocaine $(30 \mathrm{mg}$ ) were administered intravenously immediately after venoclysis. After anesthesia induction, capnographic monitoring was added and the neuromuscular blockade was evaluated using acceleromyography (TOF Watch SX, Bluestar Enterprises, 
Inc, Omaha, NE). Induction and maintenance of anesthesia were performed as follows:

- Group V: remifentanil, induction dose $0.5 \mu \mathrm{g} \mathrm{kg}^{-1} \mathrm{~min}^{-1}$ for 3 minutes, followed by a maintenance dose of $0.3 \mu \mathrm{g}$ $\mathrm{kg}^{-1} \mathrm{~min}^{-1}$. Propofol, initial bolus $\left(2.0 \mathrm{mg} \mathrm{kg}{ }^{-1}\right)$ followed by infusion at 4 to $6 \mathrm{mg} \mathrm{kg}^{-1} \mathrm{~h}^{-1}$

- Group I: remifentanil, induction dose $0.5 \mu \mathrm{g} \mathrm{kg}^{-1} \mathrm{~min}^{-1}$ for 3 minutes, followed by a maintenance dose of $0.3 \mu \mathrm{g}$ $\mathrm{kg}^{-1} \mathrm{~min}^{-1}$. Propofol bolus $\left(2.0 \mathrm{mg} \mathrm{kg}^{-1}\right)$ followed by maintenance with $2 \%$ sevoflurane in $\mathrm{O}_{2}$ /air flow (fraction of inspired oxygen, $60 \%) 2 \mathrm{~L} \mathrm{~min}^{-1}$

Rocuronium $\left(0.6 \mathrm{mg} \mathrm{kg}^{-1}\right)$ was administered to both groups before tracheal intubation, which was performed when $\mathrm{T} 1<10 \%$ on the train-of-four monitor. Ventilation was controlled by adjusting the flow volume and respiratory rate to keep the end-tidal $\mathrm{CO}_{2}$ level between 30 and $40 \mathrm{~mm} \mathrm{Hg}$. In the case of inadequate depth of anesthesia (movements, sweating, tachycardia, blood pressure increase $>10 \%$ of the preinduction value), propofol infusion or sevoflurane rate was increased (by $1 \%$ ); if this was not sufficient, the remifentanil infusion rate was also increased (by $0.1 \mu \mathrm{g} \mathrm{kg}^{-1} \mathrm{~min}^{-1}$ ). Patients who exhibited reductions in systolic arterial pressure greater than $30 \%$ or heart rate reductions to less than 50 beats $/ \mathrm{min}$ were given ephedrine $(10 \mathrm{mg})$ and atropine $(0.5$ $\mathrm{mg}$ ), respectively. Hydration was maintained with $0.9 \%$ normal saline $(500 \mathrm{~mL}$ throughout the first 30 minutes and then $\left.2 \mathrm{~mL} \mathrm{~kg}^{-1} \mathrm{~h}^{-1}\right)$. All of the participants were given dexamethasone $(8 \mathrm{mg})$ and ketoprofen $(100 \mathrm{mg})$ at the onset of surgery and dimenhydrinate $(30 \mathrm{mg})$, dipyrone $(1 \mathrm{~g})$, and morphine $\left(0.1 \mathrm{mg} \mathrm{kg}^{-1}\right) 15$ minutes before the end of the procedure. Atropine $\left(0.01 \mathrm{mg} \mathrm{kg}^{-1}\right)$ and neostigmine $\left(0.05 \mathrm{mg} \mathrm{kg}^{-1}\right)$ were used to achieve T4/T1 $>0.9$ on the train-of-four monitor. Extubation was performed after awakening. When stable vital signs and respiration were confirmed, all patients were transferred to the postanesthesia care unit (PACU).

Data related to the occurrence of pain, nausea, vomiting, and hypothermia (body temperature $<36^{\circ} \mathrm{C}$ ) at the $\mathrm{PACU}$ were recorded, as was the length of stay in the PACU. Pain was assessed every 15 minutes using a $0-10$ numeric pain rating scale, where zero meant no pain and 10 the worst imaginable pain. Morphine (1-2 mg) was administered intravenously every 10 minutes to maintain the pain score lower than $4(1 \mathrm{mg}$ when the pain score was $<7$ and $2 \mathrm{mg}$ when it was $\geq 7$ ). After discharge from the PACU (minimum stay 60 minutes and Aldrete \& Kroulik index $>9$ ), all of the participants were given ketoprofen $(100 \mathrm{mg}$ ) every 12 hours and dipyrone $(30 \mathrm{mg}$ $\mathrm{kgC}:\left|S P S \backslash n e w \_w m s \_n a h s \backslash d i s t\right| r e p o s \backslash j p 61 \backslash j \mathrm{ca} 08536 \backslash \mathrm{mg} . \mathrm{kg}^{-1}$, maximum $1 \mathrm{~g}$ ) every 6 hours intravenously. Whenever patients judged that their analgesia was insufficient, tramadol $(100 \mathrm{mg})$ was administered intravenously at 8 -hour minimum intervals as needed. Postoperative nausea and vomiting (PONV) were treated with dimenhydrinate $(30 \mathrm{mg}$ ) intravenously. Pain score, use of analgesics, and the occurrence of nausea, vomiting, and other complications during the hospital ward stay were recorded.

The quality of postoperative functional recovery was assessed by the QoR-40 questionnaire, which assesses 5 dimensions of recovery (physical comfort, 12 items; emotional state, 7 items; physical independence, 5 items; physiological support, 7 items; and pain, 7 items). Each item was rated on a 5-point Likert scale: none of the time, some of the time, usually, most of the time, and all the time. The total score on the QoR-40 ranges from 40 (poorest quality of recovery) to 200 (best quality of recovery). The QoR-40 was administered by a blind investigator 24 hours after surgery. The primary outcome of interest was the QoR-40 score; however, the following data were also recorded: age, sex, physical status, body mass index, type of surgery, and length of PACU and hospital stay.

Comparison of quantitative variables between the groups was performed by means of Student $t$ test and the Wilcoxon rank sum test if their respective distributions were normal or asymmetric. Proportions were compared between the groups using the $\chi^{2}$ test or Fisher exact test as needed. Normality was assessed through visual inspection of histograms and the Shapiro-Wilk test. The categorical variables are described as absolute (relative) frequencies, and the continuous variables are described as means \pm SDs or medians (interquartile ranges). Statistical significance ( $P$ value) was assessed by means of a 2-tailed test in all instances; values less than .05 were considered to be statistically significant. Statistical analysis was performed using SAS 9.3 (Statistical Analysis System, Cary, NC).

\section{Results}

A total of 130 patients were first assessed for eligibility in this study; however, 10 were excluded because they refused participation, or met any of the exclusion criteria. Thus, 120 participants were randomly allocated to the study groups. Later, 4 participants in group I and 6 in group $V$ were excluded due to protocol deviations. Therefore, 56 participants underwent balanced anesthesia, and 54 underwent intravenous anesthesia (Fig. 1).

The 2 studied groups were comparable with respect to age $(P=.54)$, gender $(P=.69)$, physical status $(P=.57)$, and distribution of planned interventions $(P=.6)$. The characteristics of the patients who were included in the study are presented in Table 1.

\subsection{Primary outcome}

The QoR-40 questionnaire exhibited satisfactory internal consistency (Cronbach $\alpha=.75$ ). All of the participants responded to the QoR-40 questionnaire without any difficulties. The postoperative QoR-40 scores are presented in Table 2. No differences were detected in the total or individual 
dimension scores between the 2 studied groups. Similarly, the total and individual dimension scores are comparable when we analyzed the QoR-40 responses regarding sex and anesthesia technique (Table 3).

\subsection{Secondary outcome}

The length of PACU stay was comparable between the groups $(P=.97)$. During the PACU stay, 2 patients in group $\mathrm{I}$ and 7 patients in group $\mathrm{V}$ presented with shivering $(P=$ .09 ), and 9 patients in group I vs 6 patients in group $V$ presented with hypothermia $(P=.58)$. The incidence of urinary retention was comparable between the 2 studied groups as well $(P=.24)$. Occurrence of PONV was similar at PACU in both groups $(P=.39$; Table 4$)$.

Patient pain incidence at the PACU assessed by a numeric rating scale was similar in both groups $(P=.80)$. The use of morphine at PACU was also comparable between groups I and $\mathrm{V}(P=.42)$. Similarly, pain $(\mathrm{P}=1.0)$ and tramadol use $(P=.44)$ at ward stay were comparable between the studied groups (Table 5).

\section{Discussion}

This study compared the quality of recovery from 2 anesthetic techniques as assessed from the patients' perspective through the application of a specific validated questionnaire.
Table 1 Patients characteristics in both groups (intravenous [V] and inhalation $[\mathrm{I}]$ anesthesia)

\begin{tabular}{llll}
\hline & $\begin{array}{l}\text { Group I } \\
(\mathrm{n}=56)\end{array}$ & $\begin{array}{l}\text { Group V } \\
(\mathrm{n}=54)\end{array}$ & $P$ \\
\hline Age (y) & $39.3 \pm 12.7$ & $37.9 \pm 11.5$ & .54 \\
ASA & & & .69 \\
$\quad$ I & $39(70 \%)$ & $35(65 \%)$ & \\
II & $17(30 \%)$ & $19(35 \%)$ & \\
Gender & & & .57 \\
$\quad$ Female & $31(55 \%)$ & $33(61 \%)$ & \\
$\quad$ Male & $25(45 \%)$ & $21(39 \%)$ & \\
Length of surgery (min) & $168.3 \pm 45.7$ & $183.1 \pm 60.3$ & .16 \\
Type of surgery & & & 0,6 \\
$\quad$ Nose & 27 & 32 & \\
Ear & 20 & 16 & \\
Throat & 3 & 1 & \\
\hline
\end{tabular}

Data are expressed as mean \pm SDs or number of patients (\%) as appropriated.

ASA $=$ American Society of Anesthesiologists.

The patient's perceived quality of recovery was similar in those receiving total intravenous vs those receiving balanced anesthesia when evaluated 24 hours after ORL surgery.

The search for techniques that achieve fast and smooth awakenings from general anesthesia resulted in increased use of remifentanil, an opioid that undergoes ultrarapid metabolism, in combination with sevoflurane (balanced technique) or propofol (total intravenous anesthesia). Several authors

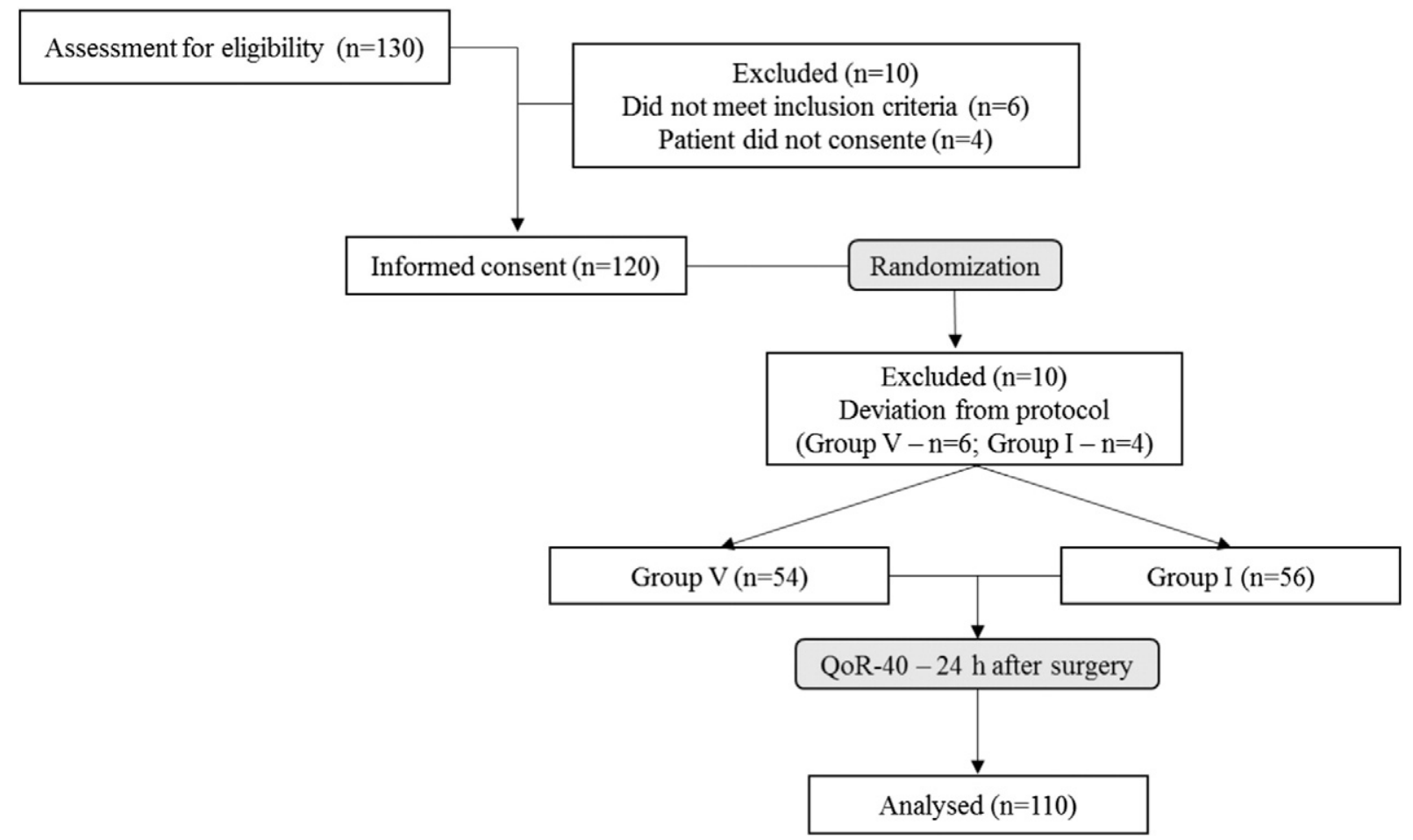

Fig. 1 Study flowchart that outlines the number of patients at each stage of the study and includes the reasons for exclusion at each stage. Moreover, the flowchart outlines randomization and analysis. 
Table 2 QoR-40 scores between inhalation and intravenous anesthesia groups postoperatively

\begin{tabular}{|c|c|c|c|c|c|c|c|c|c|}
\hline \multirow[t]{2}{*}{ Dimension } & \multicolumn{4}{|c|}{ Inhalation anesthesia } & \multicolumn{4}{|c|}{ Intravenous anesthesia } & \multirow[t]{2}{*}{$P$} \\
\hline & $\mathrm{n}$ & Median & 1st quartile & 3rd quartile & $\mathrm{n}$ & Median & 1st quartile & 3rd quartile & \\
\hline Physical comfort & 56 & 55.0 & 53.0 & 58.0 & 54 & 56.0 & 51.0 & 59.0 & .7 \\
\hline Emotional status & & 43.0 & 41.5 & 44.5 & & 43.0 & 42.0 & 45.0 & .28 \\
\hline Psychological support & & 40.0 & 38.5 & 40.0 & & 40.0 & 39.0 & 40.0 & .22 \\
\hline Physical independence & & 18.0 & 17.0 & 20.0 & & 19.0 & 17.0 & 20.0 & .18 \\
\hline Pain & & 34.0 & 32.0 & 35.0 & & 34.0 & 31.0 & 35.0 & .75 \\
\hline Total QoR-40 & & 189.5 & 183.0 & 193.0 & & 190.5 & 183.0 & 195.0 & .33 \\
\hline
\end{tabular}

Data are presented as medians (interquartile ranges).

QoR-40 = Quality of Recovery-40.

have compared these 2 techniques regarding different outcomes, and each had individual advantages. However, the traditional assessment of quality of recovery does not address the patient's perspective, and focus mainly in recovery of consciousness and stable vital signs. Assessment of patient satisfaction and quality of recovery from anesthesia emerged quite recently as a relevant option in studies seeking to compare different therapeutic modalities. Patients regard quality of recovery as a matter of improvement of comfort and its impact on their quality of life in the early postoperative period [10]. Accordingly, such surveys provide anesthesiologists with the possibility of assessing the patients' concerns and opinions and including them in actual practice. Some studies assessed the characteristics of recovery and satisfaction of patients subjected to anesthesia with propofol or sevoflurane and did not identify any significant differences between the 2 techniques [11-13]. In a multicenter study, Hofer et al [1] compared the quality of recovery of patients subjected to total intravenous (TIVA) vs balanced inhalation anesthesia and found that TIVA was associated with higher levels of postoperative wellbeing. Those authors used the Adjective Mood
Scale and the State-Trait-Anxiety Inventory as assessment instruments. Although other methods to evaluate quality of recovery have been suggested, the QoR-40 [2] questionnaire is currently considered to be the best tool, as determined in 2 qualitative reviews and 1 quantitative systematic review $[3,14,15]$.

Lee et al [4], using the QoR-40 instrument, recently found that female patients undergoing thyroid surgery perceived a better quality of recovery when TIVA was used when compared with inhalation anesthesia with desflurane. Among the 5 dimensions of the QoR-40, physical comfort and physical independence were significantly better in the TIVA group [4]. The hypothesis that intravenous anesthesia affords better quality of recovery was tested in the present study through the application of the QoR-40. Responding to the full questionnaire took 10 minutes on average, according to the 2 participating examiners, and no participants had difficulties understanding the questionnaire. Differently from the study by Lee et al, our results showed no difference among the groups regarding both the total QoR-40 scores and the 5 individual domains assessed by the QoR-40 questionnaire. These conflicting

Table 3 Total and individual dimension QoR-40 scores regarding to sex and anesthesia technique.

\begin{tabular}{|c|c|c|c|c|c|c|c|c|c|}
\hline \multirow[t]{2}{*}{ Dimension } & \multicolumn{4}{|c|}{ Inhalation anesthesia } & \multicolumn{4}{|c|}{ Intravenous anesthesia } & \multirow[t]{2}{*}{$P$} \\
\hline & $\mathrm{n}$ & Median & 1st quartile & 3rd quartile & $\mathrm{n}$ & Median & 1st quartile & 3rd quartile & \\
\hline \multicolumn{10}{|l|}{ Female } \\
\hline Physical comfort & 31 & 55.0 & 53.0 & 57.0 & 33 & 54.0 & 51.0 & 59.0 & .66 \\
\hline Emotional status & & 43.0 & 42.0 & 45.0 & & 43.0 & 41.0 & 44.0 & .65 \\
\hline Physiological support & & 40.0 & 38.0 & 40.0 & & 40.0 & 39.0 & 40.0 & .22 \\
\hline Physical independence & & 18.0 & 17.0 & 20.0 & & 19.0 & 17.0 & 20.0 & .27 \\
\hline Pain & & 33.0 & 32.0 & 35.0 & & 34.0 & 31.0 & 35.0 & .23 \\
\hline Total QoR-40 & & 188.0 & 184.0 & 193.0 & & 190.0 & 180.0 & 194.0 & .80 \\
\hline \multicolumn{10}{|l|}{ Male } \\
\hline Physical comfort & 25 & 56.0 & 54.0 & 58.0 & 21 & 56.0 & 54.0 & 58.0 & .95 \\
\hline Emotional status & & 42.0 & 41.0 & 44.0 & & 43.0 & 43.0 & 45.0 & .18 \\
\hline Physiological & & 40.0 & 39.0 & 40.0 & & 40.0 & 39.0 & 40.0 & .69 \\
\hline Physical independence & & 18.0 & 17.0 & 20.0 & & 19.0 & 18.0 & 20.0 & .42 \\
\hline Pain & & 34.0 & 33.0 & 35.0 & & 34.0 & 33.0 & 35.0 & .83 \\
\hline Total QoR-40 & & 191.0 & 182.0 & 194.0 & & 194.0 & 186.0 & 196.0 & .38 \\
\hline
\end{tabular}

Data are presented as medians (interquartile ranges).

QoR-40 = Quality of Recovery-40. 
Table 4 Secondary outcome measurements: length of PACU stay, incidence of shivering, urinary retention, hypothermia, and nauseas and vomiting at PACU

\begin{tabular}{lcll}
\hline & $\begin{array}{l}\text { Group I } \\
(\mathrm{n}=56)\end{array}$ & $\begin{array}{l}\text { Group V } \\
(\mathrm{n}=54)\end{array}$ & $P$ \\
\hline Length of PACU stay $(\mathrm{min})$ & $60(60-60)$ & $60(60-70)$ & .97 \\
Shivering & $2(4 \%)$ & $7(13 \%)$ & .09 \\
Urinary retention & $0(0 \%)$ & $2(4 \%)$ & .24 \\
Hypothermia & $9(16 \%)$ & $6(11 \%)$ & .58 \\
PONV & $5(9 \%)$ & $2(4 \%)$ & .39 \\
\hline
\end{tabular}

Group I = inhalation anesthesia; group $\mathrm{V}=$ intravenous anesthesia; $\mathrm{PACU}=$ postanesthesia care unit; $\mathrm{PONV}=$ postoperative nauseas or vomiting. Data are expressed as medians (interquartile ranges) or number of patients (\%) as appropriated.

results may be explained by the fact that the Korean written version of the QoR-40 questionnaire has not been formally validated, whereas the instrument was translated, adapted, and validated for the Portuguese language in 2010 [16]. Moreover, the lack of difference between groups may be due to the fact that we included patients from both genders in the present study. However, when we compared the results according to gender, there were also no significant differences between the groups. Regarding the use of desflurane or sevoflurane for maintenance of anesthesia, meta-analysis of studies comparing these 2 anesthetics indicated that there are no significant differences in postoperative recovery including the occurrence of PONV [17]. Besides the patient's quality of recovery assessed by the QoR-40, other undesirable events that are considered as possible causes of patient dissatisfaction were assessed. No differences were identified in the incidence rates of shivering, urinary retention, or hypothermia between the participants subjected to intravenous or inhalation anesthesia. There seems to be a consensus that the incidence of PONV is higher when inhalation anesthesia is used [8]. However, this association was not detected in the present study. Hofer et al [1] compared the quality of recovery of patients subjected to

Table 5 Secondary outcome measurements: incidence of postoperative pain at PACU, incidence of postoperative pain at ward, and postoperative medication use at PACU and at ward

\begin{tabular}{lccc}
\hline & $\begin{array}{l}\text { Group I } \\
(\mathrm{n}=56)\end{array}$ & $\begin{array}{c}\text { Group V } \\
(\mathrm{n}=54)\end{array}$ & $P$ \\
\hline Pain at PACU & $48(86 \%)$ & $45(83 \%)$ & .80 \\
Pain score 0 & $8(14 \%)$ & $9(17 \%)$ & \\
Pain score > 0 & $2(4 \%)$ & $5(9 \%)$ & .42 \\
Morphine use at PACU & $26(46 \%)$ & $25(46 \%)$ & 1.0 \\
Pain at ward & $30(54 \%)$ & $29(54 \%)$ & \\
Pain score 0 & $5(9 \%)$ & $2(4 \%)$ & .44 \\
Pain score > 0 & & & \\
Tramadol use at ward & & & \\
Group I = inhalation anesthesia; Group V $=$ intravenous anesthesia; \\
PACU = postanesthesia care unit. Data are expressed as number of patients \\
(\%).
\end{tabular}

intravenous or inhalation anesthesia and reported a high incidence of PONV, especially among the participants who had been given sevoflurane, which might account for the better quality of recovery reported by the patients subjected to intravenous anesthesia. Lack of prophylactic administration of antiemetic agents might explain the discrepancy between results of Hofer et al [1] and the present study. Our protocol included systematic administration of dexamethasone and ondansetron to all participants.

The results of the present study also show that pain intensity and morphine use were similar in both groups. Because only individuals subjected to ORL surgery were included in the present study, it is not possible to assert with any degree of certainty that this finding will hold true for patients subjected to other surgical procedures with greater potential to postoperative pain. It is clear that our study present other additional limitations. First, the sample size was calculated for the detection of differences in the total QoR-40 scores between groups. Accordingly, the sample size may be inadequate to compare the individual dimensions of the instrument between groups. Second, we did not conduct a long-term follow-up in the patients who were enrolled in the present study. It has been shown that the quality of recovery on the day after an anesthetic procedure can be associated with patient's perception of recovery weeks or, even, years afterward. A poorquality recovery on the days after surgery can predict a poor score of recovery assessed by the QoR- 40 months after surgery [18]. Finally, the present study did not address any aspect of costs and economy. Although TIVA is supposed to be more expensive than inhalation anesthesia [19-21], costbenefit analysis and cost assessment in anesthesia have proved to be a very complex subject.

To conclude, we showed that there was no difference in the quality of recovery of patients subjected to ORL surgical procedures under balanced or TIVA general anesthesia when quality of recovery was assessed by the QoR-40 instrument. The lack of difference was demonstrated on the total QoR-40 score as well as on the individual domains of the questionnaire.

\section{Acknowledgments}

Gustavo Farinha Pinto Saraiva and Nathália Vianna de Matos Leite were granted a scholarship from PIBIC/CNPq.

\section{References}

[1] Hofer CK, Zollinger A, Büchi S, Klaghofer R, Serafino D, Bühlmann S, et al. Patient well-being after general anaesthesia: a prospective, randomized, controlled multi-centre trial comparing intravenous and inhalation anaesthesia. Br J Anaesth 2003;91:631-7.

[2] Myles PS, Weitkamp B, Jones K, Melick J, Hensen S. Vality and reliability of a postoperative quality of recovery score: the QoR-40. Br J Anaesth 2000;84:11-5. 
[3] Gornall BF, Myles PS, Smith CL, Burke JA, Leslie K, Pereira MJ, et al. Measurement of quality of recovery using the QoR-40: a quantitative systematic review. Br J Anaesth 2013;111:161-9.

[4] Lee WK, Kim MS, Kang SW, Kim S, Lee JR. Type of anaesthesia and patient quality of recovery: a randomized trial comparing propofolremifentanil total i.V. Anaesthesia with desflurane anaesthesia. Br J Anaesth 2015;4:663-8

[5] Saklad M. Grading of patients for surgical procedures. Anesthesiology 1941;2:281-4.

[6] Casati A, Putzu M. Anesthesia in the obese patient: pharmacokinetic considerations. J Clin Anesth 2005; 17:134-45.

[7] Chapman R, Plaat F. Alcohol and anaesthesia. Contin Educ Anesth Crit Care Pain 2009;9:10-3.

[8] Hernandez M, Birnbach DJ, Van Zundert AAJ. Anesthetic management of the illicit-substance-using patient. Curr Opin Anaesthesiol 2005;18 314-24.

[9] Castro-Alves LJS, de Azevedo VFL, Braga TFF, Gonçalves AC, de Oliveira GS. The effect of neuroaxial versus general anesthesia techniques on postoperative quality and analgesia after abdominal hysterectomy: a prospective, randomized, controlled trial. Anesth Analg 2011;113: 1480-6.

[10] Gill TM, Feinstein AR. A critical appraisal of the quality of quality-oflife measurements. JAMA 1994;272:619-26.

[11] Fish WH, Hobbs AJ, Daniels MV. Comparison of sevoflurane and total intravenous anaesthesia for daycase urological surgery. Anaesthesia 1999;54:1002-6.

[12] Godet G, Watremez C, El Kettani C, Soriano C, Coriat P. A comparison of sevoflurane, target-controlled infusion propofol, and propofol/ isoflurane anesthesia in patients undergoing carotid surgery: a quality of anesthesia and recovery profile. Anesth Analg 2001;93: 560-5.
[13] Montes FR, Trillos JE, Rincón IE, Giraldo JC, Rincón JD, Vanegas MV, et al. Comparison of total intravenous anesthesia and sevofluranefentanyl anesthesia for outpatient otorhinolaryngeal surgery. J Clin Anesth 2002;14:324-8

[14] Herrera FJ, Wong J, Chung F. A systematic review of postoperative recovery outcomes measurements after ambulatory surgery. Anesth Analg 2007;10:63-9.

[15] Kluivers KB, Riphagen I, Vierhout ME, Brölmann HAM, De Vet HCW Systematic review on recovery specific quality-of-life instruments. Surgery 2008;143:206-15

[16] Schwerdtfeger CMMA. Qualidade de Recuperação em Anestesia: Abordagem da Satisfação dos Pacientes Submetidos ao Procedimento Anestésico [Quality of recovery from anesthesia: approach based on the satisfaction of patients subjected to anesthetic procedures]. [Thesis] Bauru: Hospital de Reabilitação de Anomalias Craniofaciais, Universidade de São Paulo; 2010 1-144.

[17] Macario A, Dexter F, Lubarsky D. Meta-analysis of trials comparing postoperative recovery after anaesthesia with sevoflurane or desflurane. Am J Health Syst Pharm 2005;62:63-8.

[18] Myles PS, Hunt JO, Fletcher H, Solly R, Woodward D, Kelly S. Relation between quality of recovery in hospital and quality of life at 3 months after cardiac surgery. Anesthesiology 2001;95:862-7.

[19] Smith I, Terhoeve PA, Hennart D, Feiss P, Harmer M, Pourriat JL, et al. Multicentre comparison of the costs of anaesthesia with sevofuorane or propofol. Br J Anaesth 1999;83:564-70.

[20] Sneyd JR. Costs of sevoflurane and propofol anaesthesia. Br J Anaesth 2000;84:418-9.

[21] Visser K, Hassink EA, Bonsel GJ, Moen J, Kalkman CJ. Randomized controlled trial of total intravenous anesthesia with propofol versus inhalation anesthesia with isoflurane-nitrous oxide: postoperative nausea with vomiting and economic analysis. Anesthesiology 2001;95:616-26. 